\title{
Economist promises aid to Italian research
}

Rome. "You can't remain both wealthy and stupid for more than one generation", says Romano Prodi, professor of economics at the University of Bologna - and a leading contender as Italy's next prime minister.

This is why Prodi puts education and science at the top of his political agenda. Most economic indicators, he says, show that Italy, particularly the north, is very wealthy, but urgent steps are needed to protect the next generation from the country's chaotic state.

Among other things, he says, this means considerably increased investment in science, and greater independence of universities from the state in order to bring together basic science and industrial needs.

Prodi, who is himself not attached to any political party, leads the centre-left coalition which is currently fighting the conservative forces led by the former prime minister, Silvio Berlusconi, for power in Italy. Elections could be as early as the autumn.

Before his appointment at Bologna, Prodi headed the Istituto per la Ricostruzione Industriale (IRI), the major Italian public holding company, throughout the 1980 s, and took up the position again in 1993 to oversee Italy's privatization programme. (He resigned when Berlusconi came to power last year.)

Prodi's background has given him strong views on the importance of science and research for industrial success. He points out that Italy is capable of world-class

\section{UK projects vie for millenium money}

London. Projects designed

to popularize science and protect the natural environment figure prominently on the short-list for a slice of $£ 1.6$ billion from National Lottery funds that the British government has reserved for "original and innovative schemes" to celebrate the beginning of the next century.

Proposals short-listed as potential recipients of Jodrell Bank: hoping to popularize radioastronomy. Millennium funds - one fifth of the lottery proceeds are being devoted to social projects - include a £110.8-million scheme for a hightechnology campus in Birmingham, an £88-million plan to build a national science centre in a derelict quay area of Glasgow, and a £14-million exhibition centre, also in Scotland, on the work of Alfred Nobel and the winners of the prizes that he endowed.

There is also a $\mathbf{2 0}$-million proposal to rebuild the Jodrell Bank telescope (above) and construct a new visitors' centre. Sir Francis Graham-Smith, emeritus professor at Manchester University and former astronomer royal, says that the extra funds will enable Jodrell Bank to boost its twin role as an international centre for radioastronomy and promoter of public understanding of science.

The telescope is already due to be given a new surface to enhance its resolution, while a Cassegrain feed system will increase efficiency and allow interchangeability between frequencies. If Millennium funding is approved, says Graham-Smith, Jodrell Bank, which already caters for

\section{IMAGE \\ UNAVAILABLE FOR COPYRIGHT REASONS}

150,000 visitors every year, will also get a new control building where the public will be able to observe astronomers at work.

Other science-based projects to have reached the short-list of 83 proposals, each of which will now receive closer scrutiny from the nine Millennium Commissioners, include an electronic zoo in Bristol and $\mathbf{£ 3 5 0 , 0 0 0}$ towards a centre in the Orkney islands dedicated to "a new approach to studying scientific concepts".

There were several ambitious science projects among the 467 projects not short-listed. One of those

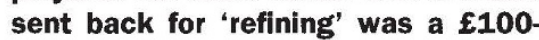
million plan for an art, science and technology centre around the national museums in South Kensington in London, known as 'Albertopolis'.

The eventual winners will be announced in September and will comprise 12 'flagship' projects and a number of smaller schemes. Each large project will receive between $£ 10$ million and $£ 50$ million, and will be expected to raise further funds from private sponsors. science - as shown by the quality of its physicists - but says that the general quality of science is patchy.

$\mathrm{He}$ also points out that, although Italy is Europe's fourth biggest economy, its total investment in research - only 1.3 per cent of its gross national product - is not much more than half that of other major European countries. Increasing this figure is one of Prodi's priorities. "But there is no point in throwing money at the problem if you don't also change the quality of the organization," he says.

$\mathrm{He}$ is, for example, highly critical of the Italian habit, widely followed within the National Research Council (CNR), of distributing funds according to the "rain principle". Under this, everyone receives a small amount of funding, but there is no concentration of resources on outstanding projects. "The CNR is a place where small powers are balanced against each other," says Prodi. "It is not an agency where strong scientific choices are being made."

But he concedes that any change in attitude will be achieved only if it is accompanied by budget increases; the capping of CNR funds in recent years has left the organization with little room for manoeuvre, as most of its money goes on salaries rather than research programmes.

Prodi is critical of Italy's over-centralization of public structures, including both the CNR and universities. "Centralization in Italy happens in a bureaucratic way, without the intrinsic strengths that it could confer", he says, pointing out, for example, the ineffective way in which resources are distributed to the country's poorer regions.

One of his priorities is therefore to extend the degree of independence given to universities by a former research minister, Antonio Ruberti, in the late 1980s. But he also acknowledges that this has political implications.

He believes that he has a recipe for forcing change without provoking further ideological and economic objections. Prodi says he would encourage all universities to form agreements with industry - but would create special funds to support those in the south "to make up for their smaller opportunities to benefit from industrial support".

Prodi is aware of Italy's poor reputation as a partner in international projects. Whereas other countries tend to have agreed financing for the duration of the collaboration, Italian scientists are all too often embarrassed by having their own funding approved only one year at a time, usually two years in arrears. "Our French and German partners get tired and send the Italians to hell", he says. It would be both possible and imperative to create more continuity in international funding, he argues.

By profession, Prodi is an industrial 
economist, and his desire for improved structures for basic science and education is accompanied by a strong belief that Italy must find ways of transferring knowledge of scientific advances to industry that exploit its unique cultural virtue of flexibility. "Our mentality is [one of] small groups, high energy," he says.

Most Italian industry is concentrated in small and medium-sized enterprises (5.2 million of industry's 6 million employees), which tend to be efficient but not innovative, with little interest in research. "You never find anyone on the board of an Italian company who comes from the research side", complains Prodi.

In addition, moving between public and private sectors in research is almost impossible; one cannot go to Fiat from the CNR and hope to return, because one will be viewed as a traitor, he says. Yet there is little career structure for researchers once they join industry.

Prodi has some specific proposals for closing the gap between basic research and industry. These include establishing the mutual recognition of career structures on the two sides, so that researchers can move freely between them without having to start at the bottom.

$\mathrm{He}$ also wants firmer control of Italy's new science park programme. A science park should be in the hands of a local consortium - including representatives of local industry and academics - to avoid problems that have arisen from, for example, professors "using the science parks simply as an extension of their own laboratories".

Even if Prodi were to succeed Lamberto Dini as prime minister, there is no guarantee that he would stay long enough in power to introduce the changes that he is proposing. But he is still taking science very seriously, both by visiting research institutes and consulting leading scientists. Many Italian scientists would like him to be able to do this from a position of political power.

Alison Abbott

\section{India and Russia to re-build links}

New Delhi. India and Russia last week announced an agreement to launch jointly up to 35 scientific projects at institutions in the two countries, and to create a common fund to meet the expenses of the scientists involved.

The agreement, which was signed in Moscow, represents a new start for IndoRussian scientific cooperation, which was called off after Russia's decision to cancel a rocket deal with the Indian Space Research Organization two years ago.

A space probe designed to study $\mathrm{X}$-rays from the sun and gamma radiation will be placed in Earth orbit in 1997. Other projects are primarily in areas of applied research.

K.S.Jayaraman

\section{UK Labour Party seeks votes through pro-science image}

London. Britain's Labour party, keen to project itself to voters as 'the party of the future', has set out to woo the scientific community with promises that science will be at the heart of the economic and social policy of any future Labour government.

John Battle, the party's science spokesman, last week promised, for example, that Labour would remedy the current lack of a strong, co-ordinated strategy for science across government, which he said resulted in initiatives by one arm of government (such as the Office of Science and Technology) often being undermined by the actions of another (such as the Department of Trade and Industry).

Battle also promised that the party would nail its colours firmly to the mast of technological change. Resurrecting the $1960 \mathrm{~s}$ pledge of the then prime minister, Harold Wilson, to forge a new Britain in "the white heat of technological

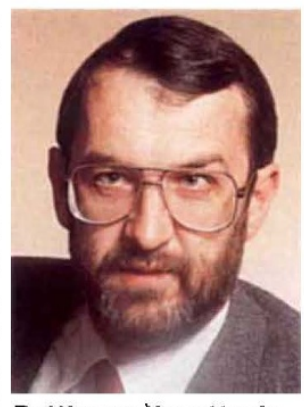

Battle: on the attack revolution", he said

Labour would distance itself from "the negative and almost anti-science cultures of the late 1970 s and 1980 s".

But, in line with the party's general preelection strategy, Battle declined to be drawn on details. In particular, while attacking an overall decline in government support for research and development, he refused to make any commitments to increased funding under a Labour government, arguing that "we cannot tell what we are going inherit when we get into to power"

Nor did he make any wholesale promises about re-nationalizing research facilities, preferring to focus his criticism - and suggested alternative strategies - on the fragmented way in which the government's privatization strategy has been carried out.

Battle was speaking at the inaugural meeting of a new group called Scientists for Labour, held at the London headquarters of the labour union Manufacturing Science Finance, whose members include university and government laboratory researchers.

Opening the meeting, Willie Russell, professor of biochemistry at the University of St Andrews, said that the spur for the creation of the group had been concern about "the collapse of scientific infrastructure and a crumbling of morale in the scientific community" in Britain.

Russell said that, for him, a key turning point had been the privatization of the
British Technology Group, a body originally established to plough back into laboratories the proceeds of exploiting publicly-funded discoveries, whose success had made it "an easy target for conservative ideologues".

Matthew Freeman, a genetics researcher with the Medical Research Council in Cambridge, and a member of the executive committee of the lobby group Save British Science, emphasized the need to protect the health and integrity of the science base.

While emphasizing that his group was political neutral, Freeman added: "We have reasonably high hopes that our views coincide with those that Labour are expressing, and that we can expect more from a Labour government than we have from the conservative government of the past 10 years."

A message from Tony Blair, the Labour leader, indicated that the party - which enjoys a substantial lead in opinion polls over the ruling conservatives under Prime Minister John Major - is keen to tap into such feelings among scientists. "Science is central to the shaping of our economic, social and political future," said Blair.

Battle reinforced this message by saying that, under Blair, Labour is committed "to help people to face up to technological change and make the world a better place," and that there is a need "to ensure that science is not feared or treated dismissively".

He was more cautious about the need for any changes in the substance of science policy under a Labour government. Following the upheavals resulting from the 1993 science white paper, for example, Battle said that the Labour Party has no desire to seek a new reshuffling of the research councils.

Indeed, he admitted to the scientists' group that "many of the ideas behind the white paper were good," endorsing, for example, the principles behind the technology foresight programme - while raising questions about the commitment with which its findings are likely to be implemented.

Battle also took issue with the 'shorttermism' which, he claimed, remains "endemic to this government's attitude to science", quoting the problem of the increasing number of researchers employed on short-term contracts.

Keen to listen to scientists' complaints about the government, the Labour Party has organized six open meetings for the autumn in different cities in Britain. A lack of resources is likely to be high on the agenda. But even those who admit they are likely to be disappointed on this score suggest that the party's general attitude towards science is likely to weigh strongly. On that measure, Battle already appears to be scoring highly.

David Dickson 